Marquette University

e-Publications@Marquette

Nursing Faculty Research and Publications

Nursing, College of

$11-1-2015$

Increasing Autism Awareness in Inner-City Churches: A Brief Report

Norah L. Johnson

Marquette University, norah.johnson@marquette.edu

Amy V. Van Hecke

Marquette University, amy.vanhecke@marquette.edu

Accepted version. Journal of Pediatric Nursing, Vol. 30, No. 6 (November/December 2015): e63-e69. DOI. (C) 2015 Elsevier Inc. Used with permission. 


\title{
Increasing Autism Awareness in Inner-City Churches: A Brief Report
}

\author{
Norah Johnson \\ College of Nursing, Marquette University, \\ Milwaukee, WI \\ Amy Van Hecke \\ Department of Psychology, Marquette University, \\ Milwaukee, WI
}

Autism diagnosis rates trail significantly in the African American community. This pre-test post-test pilot study evaluated an African American inner-city church health ambassadors (HAs) autism spectrum disorder (ASD) awareness training session. The participants included 12 HAs who attended the 1 hour training session organized by the National Baptist Convention, USA, Inc. Results of surveys showed higher mean scores post training for (1) HA attitudes about the potential for children to improve with applied behavior analysis therapy; (2) HA self-efficacy for having information about ASD screening materials; (3) strategies HAs could use to help parents/caregivers of children with developmental delays and challenging behaviors; (4) HA confidence in referrals for children with signs of ASD; (5) HA knowledge of measures to take to maximize a child's chance of receiving an ASD evaluation; and (6) HA comfort for talking to parents about children with challenging behaviors. Several of these effects were maintained 3 months later. Findings underscore the usefulness of the intervention for increasing the 
NOT THE PUBLISHED VERSION; this is the author's final, peer-reviewed manuscript. The published version may be accessed by following the link in the citation at the bottom of the page.

dissemination of knowledge about ASD and the opportunity to positively affect ASD screening, early intervention, and policy standards applicable to this vulnerable population.

Key words: Autism, Autism awareness, Early identification, Churches

Identification of and early intervention for children with autism spectrum disorder (ASD) impacts optimal child and family health outcomes (Agency for Healthcare Research and Quality, 2009 and Myers and Johnson, 2007). Children diagnosed with ASD display persistent pervasive deficits in: (1) social-emotional reciprocity, (2) nonverbal communicative behaviors and (3) relationships appropriate to the developmental level (American Psychiatric Association, 2013). The prevalence of ASD is estimated at approximately 1 in 68 children in the USA (about 3 million Americans), with four times more boys diagnosed than girls (Centers for Disease Control and Prevention, 2012). Although the behavioral and social delays characteristic of ASD are generally present by 2 years of age, the diagnosis is often made much later (Zwaigenbaum, Bryson, Lord, et al., 2009).

African-American children receive an ASD diagnosis on average 2 years later than Caucasian and Hispanic children do (Kerfeld et al., 2011, Mandell et al., 2006 and Valicenti-McDermott et al., 2012). Research suggests that they are more likely to be diagnosed with an intellectual disability than Caucasian children (Jarquin, Wiggins, Schieve, \& Van Naarden-Braun, 2011). When referred to a specialty clinic for evaluation of suspected developmental delay, AfricanAmerican children are more likely than Caucasian children to be diagnosed at first with a behavioral disorder, such as attention deficit hyperactivity disorder, adjustment disorder, or conduct disorder instead of ASD (Mandell, Ittenbach, Levy, \& Pinto-Martin, 2007).

Autism awareness is a challenge for African-American families delaying diagnosis. Without awareness of the signs of ASD, it is difficult for family members to report subtle developmental concerns that are indicative of the disorder. Literature shows that family members typically only notice and then report more noticeable milestones that children have accomplished (e.g. walking and first

[Citation Journal/Monograph Title, Vol XX, No. XX (m yyyy): pg. XX-XX. DOI. This article is @ [Publisher's Name] and permission has been granted for this version to appear in e-Publications@Marquette. [Publisher's Name] does not grant permission for this article to be further copied/distributed or hosted elsewhere without the express permission from [Publisher's Name].] 
words) (Wetherby, Brosnan-Maddox, Peace, \& Newton, 2008). Further, while there has been a reported increase in screening for ASD since the American Academy of Pediatrics recommendation for screening of all children at 18 and 24 months of age (Myers \& Johnson, 2007), the rate of screening remains low. In a 2012 study, a sample of 157 primary care physicians reported a $55 \%$ consistent use of autism screening tools (Keil, Breunig, Fleischfresser, \& Oftedahl), up from $28 \%$ in 2009 (Gillis, 2009), and up from $8 \%$ in 2006 (DosReis, Weiner, Johnson, \& Newschaffer, 2006). Barriers to screening included lack of time for screening, inadequate reimbursement for the screening, lack of office staff, and lack of training on the use of the screening tools (Keil et al., 2014). Another barrier to screening is the health care provider's (HCP) own lack of self-efficacy for the screening (Golnik, Ireland, \& Borowsky, 2009). Self-efficacy is defined as a person's belief in his or her ability to perform a designated task (Bandura, 1977). Thus, the lack of ASD awareness for families and the other barriers to screening contribute to later identification of ASD in the African-American population.

Churches are important in inner-city African-American communities. Their importance has led to the development of feasible small-group, church-based training sessions that seek to increase rates of cancer screening (Allen et al., 2014) and self-management of diabetes (Johnson et al., 2014). Currently in the USA, the Health Outreach Prevention Education Ministry (H.O.P.E.) of the nationwide Baptist Convention trains lay people to serve the community by screening for many health conditions (The National Baptist Convention, 2014). In Milwaukee, Wisconsin, the Urban Diagnostic Initiative is a local and community-based education and outreach effort, working in collaboration with the Milwaukee Center for Independence and the General Baptist State Convention. This initiative seeks to train "first lady" (i.e., pastors' wives or husbands) to be "health ambassadors" (HA) for their communities. In this HA role they contribute to: (1) recognizing ASD, (2) dispelling myths and blame, (3) emphasizing the importance of intervention, (4) coaching in how to approach parents with possible ASD children, and (5) what to do to get children diagnosed, followed by the most appropriate services. With the present pilot study, we sought to describe how participation in an ASDcurriculum impacted knowledge, attitudes, behaviors, and self-efficacy of the HAs in the community who observe children with the behaviors permission has been granted for this version to appear in e-Publications@Marquette. [Publisher's Name] does not grant permission for this article to be further copied/distributed or hosted elsewhere without the express permission from [Publisher's Name].] 
indicative of ASD. A long-term goal is the development of an HA with the knowledge and confidence to approach families of children with signs of ASD in an effort to obtain a referral for ASD screening and appropriate resources.

\section{Purpose}

The purpose of this study was to measure how training for inner-city church HAs in the signs of ASD improved their knowledge, attitudes, and self-efficacy for referral for ASD evaluation and treatment. We hypothesized that there would be improvements in HA knowledge, attitudes, and self-efficacy, and that these improvements would be maintained at 3 months.

\section{Methods}

\section{Design}

The study used pre-survey and post-survey methodology to evaluate the impact of the curriculum. Approval was obtained from the university's institutional review board.

Data were collected from the community HAs before participation, after participation, and 3 months later.

\section{Sample/Setting}

Subject sampling was by convenience, and there were no exclusion criteria for participation in the study. Fourteen HAs, who were attending an advocacy training session conducted by a local branch of the National Baptist Convention, volunteered to participate in a study that examined the effectiveness of the ASD module in their HA training. Written consent was obtained from each participant. Participants who declined were not penalized in any way, and remained at the ASD training.

The fourteen HAs were women, between the ages of 43 and 76 years $(M=53.8, S D=9.24)$. They completed the pre-training questionnaires, and of them 12 completed the post-training 
questionnaires and the 3-month telephone follow-up (Table 1). The women were pastor or deacons' wives, or church leaders, in the Milwaukee area Baptist Convention. The twelve (85.7\%) participants had children of their own, and nine (64.3\%) had grandchildren. A substantial portion did not have friends or relatives with ASD ( $n=8$, $57 \%$ ), and the majority did not have any prior ASD training ( $n=10$, $71.4 \%)$.

Table 1. Health ambassador demographics.

\section{N (\%) Mean (SD) Minimum-Maximum}

Gender

\begin{tabular}{|c|c|c|c|}
\hline Female & $14(100)$ & & \\
\hline Age (years) & 10 & $53.8(9.24)$ & $43-7$ \\
\hline \multicolumn{4}{|l|}{ Race } \\
\hline African & $14(100)$ & & \\
\hline \multicolumn{4}{|l|}{ American } \\
\hline Number of children & 13 & $2(1)$ & $0-3$ \\
\hline Number of grandchildren & 13 & $2.23(2.68)$ & $0-7$ \\
\hline \multicolumn{4}{|c|}{ Friends or relatives with ASD? } \\
\hline Yes & $3(54)$ & & \\
\hline No & $7(23)$ & & \\
\hline Don't know & $3(23)$ & & \\
\hline \multicolumn{4}{|c|}{ Past formal training on ASD? } \\
\hline Yes & $3(23)$ & & \\
\hline No & $10(77)$ & & \\
\hline
\end{tabular}

\section{Educational Intervention}

The intervention was a 45-minute long PowerPoint, instructorled, ASD awareness-training module. The curriculum was based on the self-efficacy theory (Bandura, 1977). In this theory, mastery experience, vicarious experience, emotional states, and social persuasions from others, are believed to account for feelings of competence, and confidence about performing a specific task, ultimately impacting how people behave (Bandura, 1977). Specifically, self-efficacy perceptions help determine what people do with the knowledge they obtain (Bandura, 1977).

To impart knowledge, the training module's development goals were to avoid jargon and use culturally-appropriate and culturallyspecific language. For example, instead of "self-stimulatory behavior" 
the education referred to these behaviors more concretely as "waving their hands" and "jumping up and down." To address the need to provide vicarious experience, a video was used to demonstrate each symptom domain. Since there were few commercially available videos of African-American children with ASD (Autism Speaks, 2013), we gained permission from the parent of an African-American child with ASD, who was a current university autism clinic client, to use their video for examples of behaviors. The video was accompanied by the instructor's narrative that the behaviors of this child were mistaken as a behavioral problem and not ASD initially. The child experienced a delay in diagnosis until 8 years of age.

Other components of the training included the types and range of behaviors of children with ASD, community resources, 'Learn the Signs, Act Early' resources from the Centers for Disease Control and Prevention, and content related to talking to parents. Participants were instructed to talk to families once red flags are identified, provide information on where families can obtain an ASD screening, and describe the steps for obtaining resources after the completion of screening. An African-American undergraduate research assistant tested the education at her church. Based on the church group's suggestion, pastor-approved scripture quotations were added in the educational presentation, for example: "Behold, I send you forth as sheep in the midst of wolves: be ye therefore wise as serpents, and harmless as doves" (Matthew, 10:16). Adding bible quotations tailored the education for this population and was inspirational.

\section{Measures}

Participants filled out two, paper-and-pencil, teleform questionnaires. The first was a demographics questionnaire, to describe the sample (gender, age, past experience with ASD, etc.). The second was a questionnaire that asked about their experiences, attitudes, and knowledge and self-efficacy about ASD. Since no existing scale was located in the literature, to measure these concepts for children with ASD, we developed a 15-item questionnaire based on another knowledge, attitudes, and self-efficacy screening measure used to assess knowledge, attitudes and self-efficacy for screening for intimate partner violence (Johnson et al., 2009), which had a 
Cronbach alpha $=.85$. The scales were formed following the exact wording of the questions, but with modifications specific to ASD for the present study. The self-report rating scale uses a 5-point Likert scale format ( 1 = strongly disagree and $5=$ strongly agree). The center of the scale was labeled "neutral." The scores were not totaled for the pilot study. For questions 1-4, 6-7, and 11, lower scores are indicative of more knowledge, positive attitudes, and higher self-efficacy.

\section{Procedure}

The 45-minute long training module was presented with video clips of behaviors germane to ASD. After the module was completed, on the same day, participants were asked again to complete the second questionnaire about their knowledge, attitudes, and selfefficacy for ASD awareness. Participants completed a contact form with their participant number and their phone number so that the researchers could do a follow-up screening with the second questionnaire, 3 months later. All forms were coded with a study participant number. All contact information was kept separate from the questionnaire, in a locked drawer, and was then shredded once the third questionnaire was completed. Participating HAs were told that they did not have to answer any question that they did not wish to answer, and that they could leave the study at any time. Data were collected on teleforms and scanned into SPSS 21.0.

A trained research assistant entered data. Descriptive statistics were calculated for the HAs. The two participants with missing data were removed, and not considered in any additional analyses. Frequencies were calculated for baseline behaviors. Analyses were conducted by using paired $t$ tests for the individual questions on the attitudes/beliefs and self-efficacy questionnaire. No items were reverse scored for this pilot study, as the scales were not totaled. There were not enough participants to perform factor analysis for subscales and to measure reliability. 


\section{Results}

\section{Screening Behaviors}

Frequencies for screening behavior for the HAs were calculated for two time periods: (1) pretraining and (2) 3 months later (Table 2). Pretraining, the HAs self-reported seeing a child with the following difficulties: socialization $n=7(50 \%)$, communication $n=4(28.6 \%)$, repetitive behavior $\mathrm{n}=3(21.4 \%)$, and environmental sensitivity $\mathrm{n}=3$ $(21.4 \%)$. Of those only $2(28.6 \%)$ HAs followed up with ASD referral information for the children with socialization difficulties. At the 3month follow-up, participants self-reported seeing a child with the following difficulties: socialization $n=4(28.6 \%)$, communication $\mathrm{n}=5(35.7 \%)$, repetitive behavior $\mathrm{n}=3(21.4 \%)$, and environmental sensitivity $n=1$ (14.3\%). Of those with socialization difficulty, $n=3$ (75\%) HAs followed up with ASD referral information.

Table 2. Frequencies of behaviors pre-training and 3 months post ASD training.

$\begin{array}{cc}\begin{array}{c}\text { Pre- } \\ \text { training*Yes, } \\ (\%)\end{array} & \begin{array}{c}\text { 3 Month } \\ \text { post** Yes, }\end{array} \\ 7(50) & \begin{array}{c}(\%) \\ \text { \%) }\end{array}\end{array}$

1a. Have you seen a child with trouble getting along with other children, not imitating other children, too anxious around people, trouble looking at other children or adults, or playing too much by themselves?

b. If yes did you refer for an ASD evaluation?

2a. Have you seen a child with unusual speech, for example few words, strange noises instead of words, or repeating words too many times?

b. If yes did you refer for an ASD evaluation?

3a. Have you seen a child with unusual behaviors, 3 (21.4) for example, repeatedly turning light switches off and on, lining up toys in a row instead of playing with toys, moving their hands too much, jumping up and down too much, too active or not active enough.
b. If yes did you refer for an ASD evaluation?
4a. Have you seen a child with who is too 
NOT THE PUBLISHED VERSION; this is the author's final, peer-reviewed manuscript. The published version may be accessed by following the link in the citation at the bottom of the page.

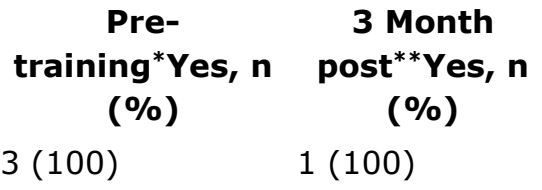

b. If yes did you refer for an ASD evaluation? 3 (100)

$*_{\mathrm{n}}=14$, some missing data.

$* * \mathrm{n}=12$, some missing data.

\section{Knowledge, Attitudes, and Self-Efficacy Questionnaire}

Mean item scores for each of the 15 questions on the knowledge, attitudes, and self-efficacy questionnaire were calculated for three time periods. These time periods were: pretraining, immediately post training, and 3 months later (Table 3 ).

Table 3. Baseline, post-training and follow up questionnaire* results.

BaselineN = 14Mean

(SD)

Attitudes and knowledge

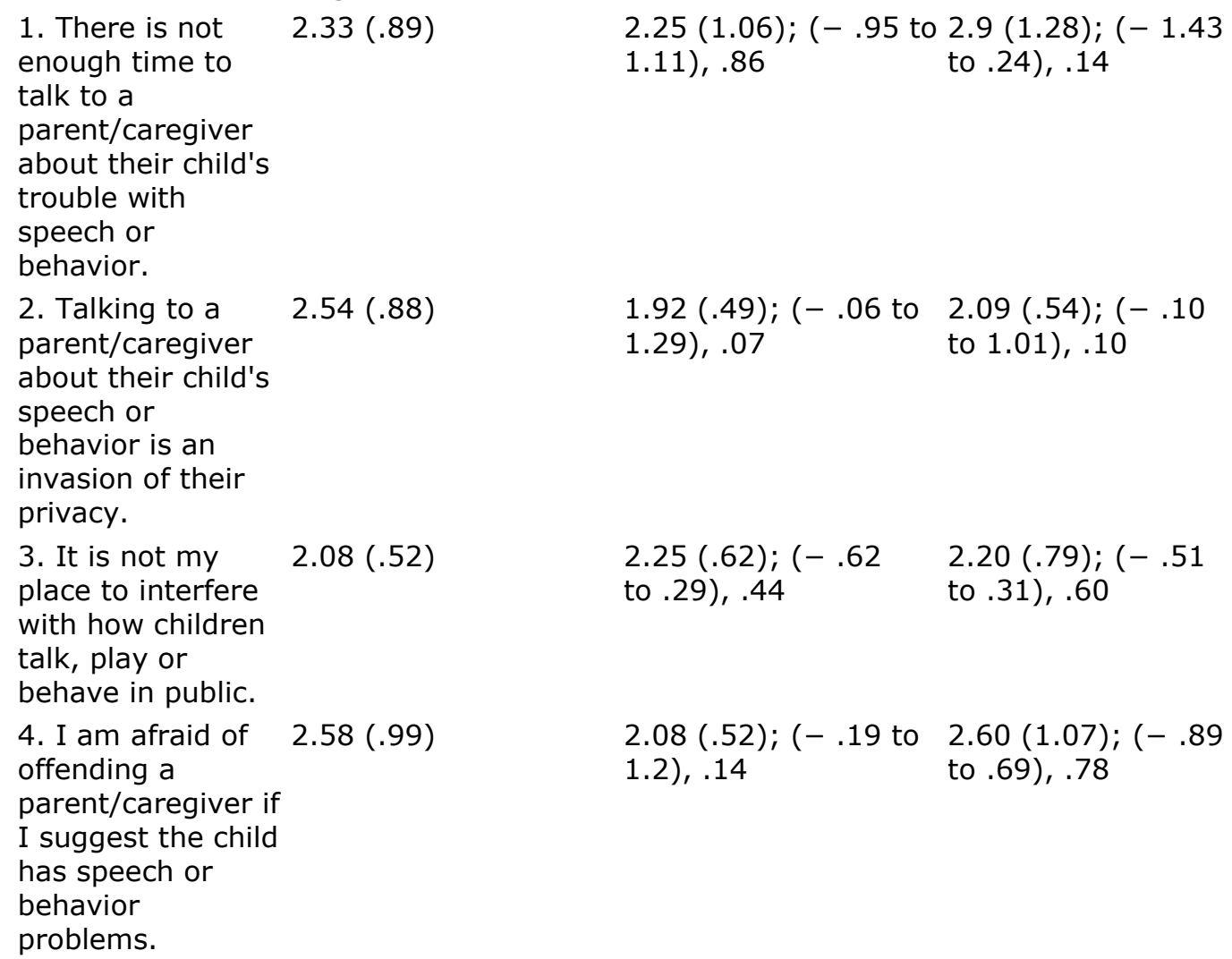

$$
2.25(1.06) ;(-.95 \text { to } 2.9(1.28) ;(-1.43
$$$$
1.11), .86 \text { to } .24), .14
$$

$1.92(.49) ;(-.06$ to

$2.09(.54) ;(-.10$

$1.29), .07$

to 1.01$), .10$

$$
\begin{array}{ll}
2.25(.62) ;(-.62 & 2.20(.79) ;(-.51 \\
\text { to } .29), .44 & \text { to } .31), .60 \\
& \\
2.08(.52) ;(-.19 \text { to } & 2.60(1.07) ;(-.89 \\
1.2), .14 & \text { to } .69), .78
\end{array}
$$

3 Month followupN = 12Mean trainingN = 12Mean (SD); comparison with baseline, mean difference (95\%CI), p

(SD); comparison with baseline, mean difference (95\%CI), p

[Citation Journal/Monograph Title, Vol XX, No. XX (m yyyy): pg. XX-XX. DOI. This article is @ [Publisher's Name] and permission has been granted for this version to appear in e-Publications@Marquette. [Publisher's Name] does not grant permission for this article to be further copied/distributed or hosted elsewhere without the express permission from [Publisher's Name].] 
NOT THE PUBLISHED VERSION; this is the author's final, peer-reviewed manuscript. The published version may be accessed by following the link in the citation at the bottom of the page.

5. Autism results in trouble with social skills, language, and behaviors.

6. A child can out grow autism.

7. It is a parent's fault if a child has autism.

8. Children with autism may make some improvements with language and behavior therapy.

\section{Self-efficacy}

9. I have ready

access to

materials to give

to parents about

where they can

get their child

screened for autism.

10. There are strategies I can use to help parents/caregivers of children with speech and behavior problems change their situation.

11. If I ask a parent/caregiver of a child that does not have autism about autism, he/she will get very angry.

12. I feel confident that I can make
BaselineN = 14Mean (SD)

$3.73(.91)$

$2.45(1.04)$

$1.42(.52)$

$4(.43)$$$
4(.43)
$$

PosttrainingN = 12Mean
(SD); comparison with baseline, mean difference (95\%CI), p

$$
3.82(.98) ;(-.85
$$$$
\text { to } .67), .80
$$

\section{Month follow- upN = 12Mean (SD); comparison with baseline, mean difference (95\%CI), p}

$3.78(1.1) ;(.60$ to .82$), .73$

$$
\begin{array}{ll}
2.45(.93) ;(-1.0 \text { to } & 2.56(1.13) ;(-.78 \\
1.0), 1.00 & \text { to } .77), 1.0 \\
1.33(.49) ;(-.42 & 1.80(.63) ;(-.78 \\
\text { to } .58), .72 & \text { to } .18), .19 \\
4.08(.50) ;(-.27 & \begin{array}{l}
4.44(.53) ;(-.71 \\
\text { to }-.03), .038
\end{array} \\
\text { to } .10), .34 & \begin{array}{l}
\end{array}
\end{array}
$$

$\begin{array}{lll}2.6(.52) & 4(.67) ;(-2.09 \text { to } & 3.8(1.04) ;(-2.06 \\ & -0.71), .001 & \text { to }-.54), .004\end{array}$

$4(.58) ;(-1.14$ to

$4.27(.47) ;(-1.47$

$-0.09), .025$

to -.35$), .005$

$2.67(.78)$

$2.67(.78) ;(-.77$

$2.22(.42) ;(-.20$

to .77$), 1.00$

to 1.00$), .17$

$3.45(.93)$

$4.09(.70) ;(-1.18$ to 3.78 (1.09);

$-0.09), .026 \quad(-1.71$ to .60$), .31$

[Citation Journal/Monograph Title, Vol XX, No. XX (m yyyy): pg. XX-XX. DOI. This article is @ [Publisher's Name] and permission has been granted for this version to appear in e-Publications@Marquette. [Publisher's Name] does not grant permission for this article to be further copied/distributed or hosted elsewhere without the express permission from [Publisher's Name].] 


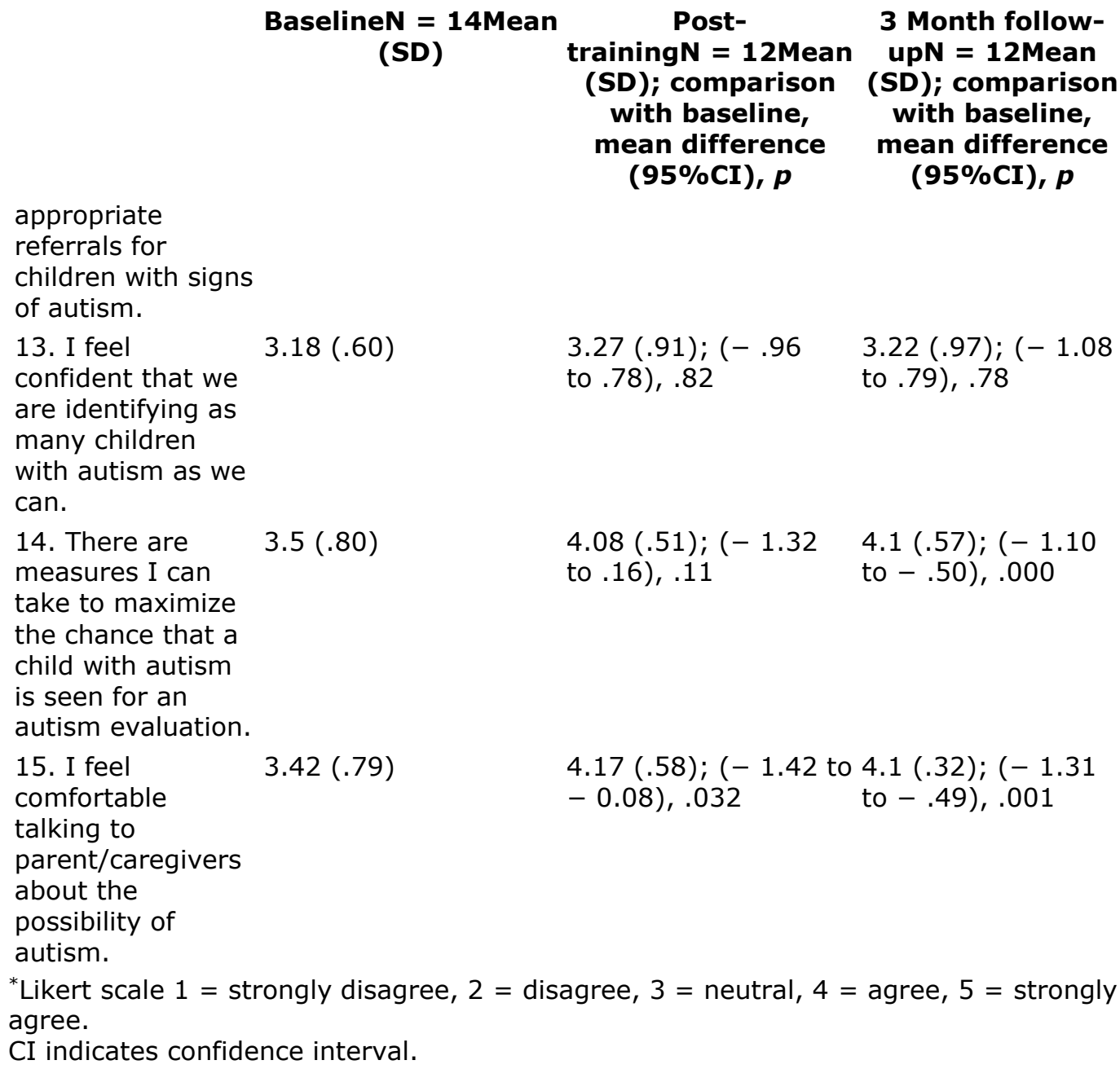

Immediately after training, none of the mean scores for the questions on attitudes and knowledge (questions 1-8) were significantly different from the pretraining mean scores. Mean scores for the self-efficacy questionnaire items (questions 9-12) showed some improvements with mean scores, specifically for: (1) question 9, which assessed confidence in having the materials to give to parents about where they can get their child screened for ASD (post $t$ $(9)=-4.53, p=.001)$, (2) question 10, which endorsed higher ratings of participants knowing strategies to help parents/caregivers of children with speech and behavior problems change their situation (post $t(12)=-2.55, p=.025$, (3) question 12, which assessed participants having more confidence in referrals for children with signs of $\operatorname{ASD}(t(10)=-2.61$, post, $p=.026)$; and (4) question 15, which 
NOT THE PUBLISHED VERSION; this is the author's final, peer-reviewed manuscript. The published version may be accessed by following the link in the citation at the bottom of the page.

assessed participant comfort talking to parents $(t(11)=-2.46$, post $p=.032)$.

\section{Three Months After Training}

Three months after training, one of the eight mean scores for the questions on knowledge and attitudes was significantly different from pretraining. There was a higher rating for question 8 , which addressed the participant perception of the potential for children to improve with language and behavior therapy 3-months later ( $t$ $(10)=-2.39, p=.038)$. Scores for this item were not different immediately after the education.

Mean scores for the self-efficacy questionnaire items showed higher ratings 3-months later, specifically for: (1) question 9, having ready access to materials to give to parents about where they can get their child screened for ASD $t(9)=-3.38, p=.004)$; (2) question 10 , endorsing higher ratings of knowing strategies to help parents/caregivers of children with speech and behavior problems change their situation $t(10)=-3.63, p=.005)$; (3) question 14, having more knowledge of measures to take to maximize child being seen for an autism evaluation $t(9)=-6.00 p<.001)$; and (4) question 15 , feeling more comfortable talking to parents $t$ (9) $=-5.01, p=.001$ ).

\section{Discussion}

Community leaders in the inner city play a central role in the awareness of the signs of ASD, since children there may be at-risk for under- or late-identification of developmental delays (Zwaigenbaum et al., 2009). An intervention was developed to increase identification and referral rates of children with ASD in an inner city AfricanAmerican population, by targeting HAs in faith-based organizations. This training of spouses of clergy taps into already-trusted resources for increasing earlier detection and referral of children for ASD evaluation. 
NOT THE PUBLISHED VERSION; this is the author's final, peer-reviewed manuscript. The published version may be accessed by following the link in the citation at the bottom of the page.

\section{Screening Behaviors}

Before the HA ASD awareness training intervention there was a low rate of evaluation recommendation behavior by the HAs, as noted in the screening behavior's survey results. Then, 3 months after the training, the results showed an increased frequency of HA recommendation for parents to have an ASD screening. Specifically, there was a change from $28.6 \%$ of children referred prior to training to $75 \%$ referred after training. This recommendation was based on social development alone. There was no change in referrals based on communication, repetitive behavior, or sensory issues, possibly suggesting that children with these signs were already being seen and diagnosed with ADHD and other behavioral disorders, as noted in previous research (Mandell et al., 2007).

The low rate of ASD evaluation contributes to a delay in diagnosis, which could be partly because of a lack of awareness of the subtler social signs of ASD (Wetherby et al., 2008) or a lack of knowledge, attitude, or poor self-efficacy about screening for ASD (Golnik et al., 2009 and Keil et al., 2014). However, past research has shown that poor self-efficacy regarding ASD screening seems to be a key variable that contributes to a high amount of known variance for behaviors about screening for ASD (Golnik et al., 2009). Thus, we developed confidence-building teaching strategies based on selfefficacy theory (Bandura, 1977). The training included inspirational scripture quotations, diagnostic information, and vicarious experience. The training included the video of an African-American child with the social symptoms of ASD. The video story of the African-American child provided vicarious experience of a real African-American child who had behavioral characteristics of ASD that was diagnosed later. All these methods are thought to help overcome the barriers to screening for ASD in this population.

\section{Immediately After Training}

In the present study, the mean scores for the knowledge and attitudes questions were not statistically different immediately after training. Although the mean scores for questions 1, 2, 4, 6 and 7 did decrease, a decrease for these particular items is in the direction of 
improvement. For example, question one stated "There is not enough time to talk to a parent/caregiver about their child's trouble with speech or behavior." Overall, based on the mean scores per item from pre-training, the HAs in this sample appeared be knowledgeable about ASD, and had a non-parent blaming attitude prior to the training. Thus, it is not surprising that the post-training scores were not significantly different. The HAs were not afraid of offending parents, either before or after the training. This lack of fear may be because they selected training based on previous knowledge of ASD, strong faith and courage, and faith-based personality characteristics of being non-judgmental.

For the self-efficacy items, there was improvement on items on the questionnaire that addressed practical barriers to screening, such as ready access to information describing the management of ASD, strategies to help children with signs of ASD, confidence to identify children with ASD, and making referrals. The HAs naturally identify with scripture passages as motivation to take an action, such as in this case to notice the social and behavioral signs of a child who may have ASD. Thus, it appears that training efforts focusing on improving self efficacy related to screening are most likely related to the improved reports of referrals at the 3-month follow up.

\section{Three Months After Training}

For the knowledge and attitudes subscale, only question 8 is statistically different at 3 months: "Children with autism may make some improvements with language and behavior therapy." It appears that, in the 3-month timespan between the post training survey and the follow up phone call survey, the participants saw an improvement in the individuals they referred. The training highlights how children can make improvements in language and behavior with evidencebased therapies (AHRQ, 2009). However, given the small sample, this finding could be due to chance.

For the self-efficacy subscale, several items sustained improvement from pre-training to 3 months (questions 9, 10, 14, and 15). These items addressed practical barriers to screening: ready access to information describing the management of ASD (question 9); strategies to help children with signs of ASD (question 10); permission has been granted for this version to appear in e-Publications@Marquette. [Publisher's Name] does not grant permission for this article to be further copied/distributed or hosted elsewhere without the express permission from [Publisher's Name].] 
comfortable talking to parents about ASD (question 15). One additional item, question 14 , showed a significant improvement in score from pretraining to 3 months out: "There are measures I can take to maximize the chance that a child with autism is seen for an autism evaluation." It appears that with more time, the small sample of participants believe they can make a difference. However, with the small sample this finding could be due to chance. Overall, the HAs appear to intuitively identify with scripture passages as motivation to take an action as reported here. Adding a module for ASD awareness training of HAs holds out hope to be potentially as effective for ASD as is already-existing training for self-management of diabetes and for cancer screening in the church setting (Allen et al., 2014 and Johnson et al., 2014). The emphasis upon building skills of self-efficacy, the lack of which has been noted in the past to be barriers to screening (Golnik et al., 2009), is the strength of this study.

\section{Limitations}

This pilot study does have limitations. The data collected were self-reported via surveys, rather than by objective measures. We cannot conclude that the intervention alone was responsible for the changes that resulted. There was no control group for comparison, because this was planned education training for the HAs. Social desirability effects could underlie improvements found. In addition, there was some missing data for behaviors after the intervention and at the 3-month follow-up. The HAs sampled represented a wide variety of ages and levels of experience with ASD. Factor analysis for the measurement scale used in the study could not be done due to the small sample size. A follow-up study that objectively measures behaviors is recommended.

\section{Conclusions}

Evaluation of the health ambassador training presented here shows that participants had increased knowledge about children making improvements with language and behavior therapy and in selfefficacy about making referrals for children to be screened for ASD. The improvements were related to a greater referral rate for children at the 3-month telephone follow up with the HAs. Involving church 
leaders may be a way to access isolated families with children with developmental delays and ASD. Inner-city community leader training about the importance of diagnosis and intervention may improve outcomes for vulnerable children and families. Future directions include conducting similar trainings for other church groups and increasing other outreach efforts, for example area barber shops and salons, Birth to Three programs, public schools, area child care centers, and area pediatricians and emergency rooms, with the goal of increasing screening and referral of children for diagnosis and early intervention services.

\section{References}

Agency for Healthcare Research and Quality, 2009. Agency for Healthcare Research and Quality. Research reviews: Comparative effectiveness of therapies for children with autism spectrum disorders. U.S. Department of Health and Human Services Agency for Healthcare Research and Quality (2009) (Retrieved March 18, 2013, from http://effectivehealthcare.ahrq.gov/healthInfo.cfm?infotype=rr\&proces sID $=106 \&$ status $=d$ )

Allen et al., 2014. J.D. Allen, J.E. Perez, L. Tom, B. Leyva, D. Diaz, M. Idali Torres.A pilot test of a church-based intervention to promote multiple cancer-screening behaviors among Latinas. Journal of Cancer Education, 29 (2014), pp. 136-143 http://dx.doi.org/10.1007/s13187013-0560-3

American Psychiatric Association, 2013. American Psychiatric Association. Diagnostic and Statistical Manual of Mental Disorders. (5th ed.) American Psychiatric Publishing, Arlington, VA (2013)

Autism Speaks, 2013. Autism Speaks. Autism speaks video glossary. Retrieved January 9, 2014, from http://www.autismspeaks.org/whatautism/video-glossary (2013)

Bandura, 1977. A. Bandura. Self-efficacy: Toward a unifying theory of behavioral change. Psychological Review, 84 (1977), pp. 191-215

Centers for Disease Control and Prevention, 2012. Centers for Disease Control and Prevention. Prevalence of autism spectrum disorders - autism and developmental disabilities monitoring network, 14 sites, United States, 2008. MMWR Surveillance Summaries, 61 (2012), pp. 1-19

DosReis et al., 2006. S. DosReis, C. Weiner, L.S. Johnson, C. Newschaffer. Autism spectrum disorder screening and management practices among general pediatric providers. Journal of Developmental \& Behavioral Pediatrics, 27 (2006), pp. S88-S94

[Citation Journal/Monograph Title, Vol XX, No. XX (m yyyy): pg. XX-XX. DOI. This article is @ [Publisher's Name] and permission has been granted for this version to appear in e-Publications@Marquette. [Publisher's Name] does not grant permission for this article to be further copied/distributed or hosted elsewhere without the express permission from [Publisher's Name].] 
NOT THE PUBLISHED VERSION; this is the author's final, peer-reviewed manuscript. The published version may be

accessed by following the link in the citation at the bottom of the page.

Gillis, 2009. J.M. Gillis. Screening practices of family physicians and pediatricians in 2 southern states. Infants and Young Children, 22 (2009), pp. 321-331

Golnik et al., 2009. A. Golnik, M. Ireland, I.W. Borowsky. Medical homes for children with autism: A physician survey. Pediatrics, 123 (2009), pp. 966-971

Jarquin et al., 2011. V.G. Jarquin, L.D. Wiggins, L.A. Schieve, K. Van Naarden-Braun. Racial disparities in community identification of autism spectrum disorders over time; Metropolitan Atlanta, Georgia, 20002006. Journal of Developmental \& Behavioral Pediatrics, 32 (2011), pp. 179-187 http://dx.doi.org/10.1097/DBP.0b013e31820b4260

Johnson et al., 2009. N.L. Johnson, C. Klingbeil, M. Melzer-Lange, C. Humphreys, M.C. Scanlon, P. Simpson. Evaluation of an intimate partner violence curriculum in a pediatric hospital. Pediatrics, 123 (2009), pp. 562-568 http://dx.doi.org/10.1542/peds.2007-3121

Johnson et al., 2014. P. Johnson, M. Thorman Hartig, R. Frazier, M. Clayton, G. Oliver, B.W. Nelson, et al. Engaging faith-based resources to initiate and support diabetes self-management among African-Americans: A collaboration of informal and formal systems of care. Health Promotion Practice, 15 (2014), pp. 71S-82S http://dx.doi.org/10.1177/1524839914543012

Keil et al., 2014. A. Keil, C. Breunig, S. Fleischfresser, E. Oftedahl. Promoting routine use of developmental and autism-specific screening tools by pediatric primary care clinicians. Western Medical Journal, 113 (2014), pp. 227-231

Kerfeld et al., 2011. C.I. Kerfeld, J.M. Hoffman, M.A. Ciol, D. Kartin. Delayed or forgone care and dissatisfaction with care for children with special health care needs: the role of perceived cultural competency of health care providers. Maternal Child Health Journal, 15 (2011), pp. 487-496 http://dx.doi.org/10.1007/s10995-010-0598-3

Mandell et al., 2006. D.S. Mandell, J. Cao, R. Ittenbach, J. Pinto-Martin. Medicaid expenditures for children with autism spectrum disorders: 1994 to 1999. Journal of Autism and Developmental Disorders, 36 (2006), pp. 475-485

Mandell et al., 2007. D.S. Mandell, R.F. Ittenbach, S.E. Levy, J.A. PintoMartin. Disparities in diagnoses received prior to a diagnosis of autism spectrum disorder. Journal of Autism and Developmental Disorders, 37 (2007), pp. 1795-1802 http://dx.doi.org/10.1007/s10803-006-0314-8 Myers and Johnson, 2007. S.M. Myers, C.P. Johnson. Management of children with autism spectrum disorders. Pediatrics, 120 (2007), pp. 11621182

[Citation Journal/Monograph Title, Vol XX, No. XX (m yyyy): pg. XX-XX. DOI. This article is @ [Publisher's Name] and permission has been granted for this version to appear in e-Publications@Marquette. [Publisher's Name] does not grant permission for this article to be further copied/distributed or hosted elsewhere without the express permission from [Publisher's Name].] 
NOT THE PUBLISHED VERSION; this is the author's final, peer-reviewed manuscript. The published version may be accessed by following the link in the citation at the bottom of the page.

The National Baptist Convention, 2014. The National Baptist Convention. from http://www.nationalbaptist.com/departments/h-o-p-e-(congress-health-initiative)/index.html (2014)

Valicenti-McDermott et al., 2012. M. Valicenti-McDermott, K. Hottinger, R. Seijo, L. Shulman. Age at diagnosis of autism spectrum disorders. Journal of Pediatrics, 161 (2012), pp. 554-556 http://dx.doi.org/10.1016/j.jpeds.2012.05.012

Wetherby et al., 2008. A.M. Wetherby, S. Brosnan-Maddox, V. Peace, L. Newton. Validation of the infant-Toddler checklist as a broadband screener for autism spectrum disorders from 9 to 24 months of age. Autism: The International Journal of Research and Practice, 12 (2008), pp. 487-511

Zwaigenbaum et al., 2009. L. Zwaigenbaum, S. Bryson, C. Lord, et al. Clinical assessment and management of toddlers with suspected autism spectrum disorder: Insights from studies of high-risk infants.

Pediatrics, 123 (2009), pp. 1383-1391 